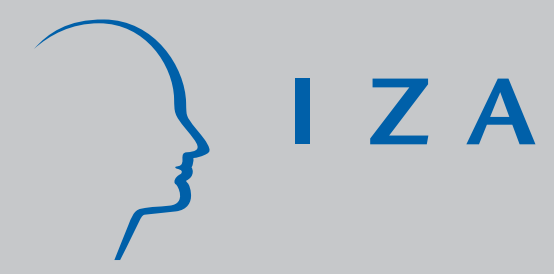

IZADP No. 1010

Re-Employment Bonuses in a Signalling Model of Temporary Layoffs

Nuria Rodriguez-Planas

February 2004 


\title{
Re-Employment Bonuses in a Signalling Model of Temporary Layoffs
}

\author{
Nuria Rodriguez-Planas \\ Mathematica Policy Research and IZA Bonn
}

Discussion Paper No. 1010

February 2004

\author{
IZA \\ P.O. Box 7240 \\ 53072 Bonn \\ Germany \\ Phone: +49-228-3894-0 \\ Fax: +49-228-3894-180 \\ Email: iza@iza.org
}

Any opinions expressed here are those of the author(s) and not those of the institute. Research disseminated by IZA may include views on policy, but the institute itself takes no institutional policy positions.

The Institute for the Study of Labor (IZA) in Bonn is a local and virtual international research center and a place of communication between science, politics and business. IZA is an independent nonprofit company supported by Deutsche Post World Net. The center is associated with the University of Bonn and offers a stimulating research environment through its research networks, research support, and visitors and doctoral programs. IZA engages in (i) original and internationally competitive research in all fields of labor economics, (ii) development of policy concepts, and (iii) dissemination of research results and concepts to the interested public.

IZA Discussion Papers often represent preliminary work and are circulated to encourage discussion. Citation of such a paper should account for its provisional character. A revised version may be available on the IZA website (www.iza.org) or directly from the author. 
IZA Discussion Paper No. 1010

February 2004

\section{ABSTRACT \\ Re-Employment Bonuses in a Signalling Model of Temporary Layoffs*}

Temporary layoffs are an important feature of the United States labor market. If these employer-employee relationships exist because of valuable job-matches, unemployment among high-productivity laid-off workers may be optimal from societal perspective. However, because of asymmetric information, low-productivity workers may behave strategically, and choose unemployment instead of low-wage jobs, resulting in an inefficient level of unemployment. This paper shows that in such cases, a re-employment bonus may give the correct incentives to laid-off workers and achieve the optimal equilibrium. The paper analyzes the equity properties of such a policy and its cost effectiveness. Finally, the model fits the data and offers several policy implications.

JEL Classification: J63, J64, J65

Keywords: temporary layoffs, recall expectations, unemployment, signalling and re-employment bonus demonstrations

Nuria Rodriguez-Planas

Mathematica Policy Research, Inc.

600 Maryland Ave., S.W., Suite 550

Washington D.C., 20024-2512

USA

Tel.: +1 2022643449

Fax: +1 2028631763

Email:nplanas@mathematica-mpr.com

\footnotetext{
* The views of this paper do not necessarily reflect those of Mathematica Policy Research, Inc., or its staff. The author thanks Kevin Lang for substantial helpful advice and Eli Berman, Peter Doeringer, Maia Guell, Lawrence Katz, Peter Kuhn, Sheena McConnell, Andrew Weiss, two anonymous referees, and participants at the American Economic Association 2001 meetings for additional comments. Financial assistance was provided by fellowships from the Bank of Spain and from the Brookings Institution.
} 


\section{INTRODUCTION}

Many economists have studied the effect of the layoff-rehire process on unemployment duration in the United States (Katz, 1986; Katz and Meyer, 1990; Anderson, 1992). In particular, Rodriguez-Planas (2003) developed and tested a signalling model of temporary layoffs, and found that at least some aspects of the search decisions of workers on temporary layoff may have a signalling component. ${ }^{1}$ The main idea behind that paper is that laid-off workers know their levels of productivity with their former employers, which are correlated with their probabilities of recall and with their productivity with a new employer. Prospective employers may gain from using workers' private information to select among job applicants who are observationally equivalent. Thus, workers with favorable information wish to signal it to employers, and they do so by taking a costly action-unemployment--for which the expected benefit is positively correlated with their private information. In this model, duration of unemployment may be positively related to post-layoff wages even among workers who are not recalled. In contrast, because workers whose plant closed cannot be recalled, longer unemployment for them should not have a positive signalling benefit. The author confirms this prediction using the 1988-2000 Displaced Workers Supplements to the Current Population Survey.

Because of productivity gains from valuable job-matches, unemployment may be socially desirable for those laid-off workers who were particularly productive with their former employer. However, because of asymmetric information, low-productivity laid-off workers may behave strategically, and choose unemployment instead of low-wage jobs, resulting in an inefficient level of unemployment. This paper analyzes the effects of a re-employment bonus on the employment decisions of laid-off workers in a signalling model of temporary layoffs. ${ }^{2}$ This paper shows that a reemployment bonus that encourages low-productivity laid-off workers to find a new job but does not discourage high-productivity laid-off workers from waiting for recall may be an optimal policy from a societal perspective. After analyzing the equity properties of such a policy, the paper examines its cost effectiveness. In addition, the signalling model of temporary layoffs helps explain existing empirical result on re-employment bonuses.

\footnotetext{
${ }^{1}$ Temporary laid-off workers are laid-off workers who initially expected to be recalled to their former job despite not having a definite recall date. Katz and Meyer (1990) find that although only 18 percent of a sample of UI recipients had a definite recall date, 75 percent expected to be recalled at the time of the UI claim.

${ }^{2}$ This paper is particularly timely and policy relevant since President Bush included in his 2003 economic stimulus plan a re-employment bonus as part of a provision to help unemployed workers find work quickly, although his proposal has not yet resulted in legislation.
} 
The paper proceeds as follows. Section I develops the theoretical model. Section II analyzes the conditions under which it is socially optimal for some temporary laid-off workers to remain unemployed. Section III shows that when it is socially optimal for some laid-off workers to reject the first-period job, there is a pareto improving re-employment bonus that induces this equilibrium. Section IV reviews the empirically observed results from the re-employment bonuses demonstrations in the United States, and examines whether the signalling model of temporary layoffs helps explain the empirical findings. The paper concludes with suggestions for further research.

\section{A Signalling Model of Temporary Layoffs}

\section{a. The Model}

There are two periods. Initially, all workers are laid off. There are two types of laid-off workers: those who were of high productivity with the original employer (G-type workers) and those who were of low productivity with the original employer (B-type worker). I assume that there is a continuum of workers of each type, $t$, where $t=B$ or $G$. The cumulative distribution of all workers is normalized to "1". The proportion of G-type workers (respectively, B-type workers) is $\alpha$ (respectively, $1-\alpha$ ), where $0<\alpha<1$. Although I do not model the layoff decision, I assume that adverse selection operates here. Thus, the fraction of B-type workers among layoffs may well exceed the fraction in the population as a whole as in Gibbons and Katz (1991).

Both the worker and the original employer know the worker's type, $t$, with that particular employer. However, laid-off workers are assumed to look identical to other potential employers. Gtype workers are more likely to be of high productivity with a new employer than B-type workers. Specifically, a type-t worker will be of high productivity with a new employer with probability $p_{t}, t=B$ or $G$ and $0<p_{B}<p_{G}<1$. Viewed alternatively, some workers are better than others, but even good workers perform badly on some jobs and bad workers perform well on others. The productivity of a G-type worker is $H$ and that of a B-type worker is $L$, with $L<H$. After the worker remains with an employer for one period, his productivity with that particular employer is revealed to both the worker and the employer, but not to other employers.

At the beginning of period one, workers are laid off. In this period, prospective employers simultaneously offer laid-off workers a first-period wage. Workers observe that wage and choose either to work for a new employer - accepting the highest wage offered (randomizing in case of a tie) or to become unemployed. If the worker becomes unemployed, his current income is $U$, where $U \geq 0$. One can think of $U$ as unemployment insurance. I assume that $U$ is financed by a constant payroll tax, $\zeta$, on all workers. I also assume that $U<L-\zeta$, to prevent workers always preferring unemployment over a job. 
At the beginning of period two, the original employer recalls those former workers who are still unemployed with probability $r_{t}, t=B$, or $G$. I assume that $r_{B}<\mathrm{r}_{G} \leq 1$. This assumption guarantees that the employer is more likely to recall high-productivity workers than low-productivity workers. ${ }^{3}$ For simplicity, I set $r_{B}=0$, (that is, the previous employer does not recall those workers who are of low productivity at his firm). Because I assumed that $r_{B}=0$, let $r_{G}=r$. Prospective employers observe that some unemployed workers are not recalled and they simultaneously offer them a wage. Unemployed workers accept the highest wage offered (randomizing in case of a tie).

Workers work over the course of period two and retire at its end.

For notational simplicity, I assume that there is no discounting between periods. Workers maximize expected lifetime income. A large finite number of employers exist, and they maximize the present value of profits. Therefore, each period employers offer a wage equal to workers' (expected) productivity. Workers and firms are risk-neutral, and they know the population parameters: $\alpha, r, p_{t}, H$, and $L$. I assume that once a worker accepts a job offer, he is precluded from receiving a future offer from a new employer. This assumption greatly simplifies the model without modifying the main results. Similarly, after accepting an offer, workers cannot quit to return to a former employer. This assumption is consistent with the behavior of laid-off workers in the U.S. Many authors have found evidence consistent with the fact that laid-off workers who expect to be recalled choose to remain unemployed (Katz 1986, Katz and Meyer 1990, Anderson 1992).

A perfect Bayesian equilibrium in this model is a strategy combination of workers and firms and a belief structure of firms such that a worker cannot increase his total expected life-time earnings by changing his first-period choice of being unemployed or taking a first-period job given the wage schedules being offered, and a firm cannot increase its expected profit by offering a different contingency wage schedule given workers' strategies and its beliefs. All proofs are in the appendix.

\section{b. Characterization of Equilibria}

Let $w_{G}$ and $w_{B}$ be the expected productivity of a G-type worker and a B-type worker, respectively, at a new job, where $w_{G}$ and $w_{B}$ are defined as:

and

$$
w_{G}=p_{G} H+\left(1-p_{G}\right) L
$$

$$
w_{B}=p_{B} H+\left(1-p_{B}\right) L
$$

The first theorem characterizes all equilibria in which some or all workers choose unemployment in the first period.

\footnotetext{
${ }^{3}$ An underlying assumption is that employers have discretion over whom to layoff and recall.
} 
Theorem 1. A necessary condition for a perfect Bayesian equilibrium in which some workers choose to remain unemployed is

$$
\left(1-p_{B}\right) \geq \frac{L-\zeta-U}{H-L}
$$

Note that $H$ and $L$ are, respectively, the maximum and minimum wages that firms would offer to workers who are unemployed one period. $L-\zeta-U$ is also the minimum loss incurred by a worker who refuses a first-period job. Thus, when (1) does not hold, the minimum cost of signalling by choosing unemployment exceeds the maximum potential expected gain.

Proof of theorem 1. Suppose that there is an equilibrium in which some workers prefer to wait unemployed than to accept the job right away. Then,

$$
\begin{aligned}
& U+r H+(1-r) w_{2} \geq w_{1}+w_{G}-\zeta \\
& U+w_{2} \geq w_{1}+w_{B}-\zeta
\end{aligned}
$$

where $w_{1}$ and $w_{2}$ are the wages offered to displaced workers who accept a job in the first period and in the second period, respectively. Consistency requires that $w_{1} \geq L$ and $w_{2} \leq H$. Inequalities (2a) and (2b) become

$$
\begin{aligned}
& H \geq L-U-\zeta+p_{G} H+\left(1-p_{G}\right) L \\
& H \geq L-U-\zeta+p_{B} H+\left(1-p_{B}\right) L
\end{aligned}
$$

respectively, and since $p_{B}<p_{H}$, inequality (1) follows.

Depending on parameter values, there are four possible equilibria including an uninteresting one with no unemployment (which I do not discuss). In the remaining equilibria all G-type workers are unemployed in the first period. B-type workers may be all employed (the fully separating equilibrium for which conditions are given in lemma 1), some employed and some unemployed (the semi-separating equilibrium for which conditions are given in lemma 2) or all unemployed (the pooling equilibrium for which conditions are given in lemma 3). The parameters values uniquely determine which of these equilibria applies.

Lemma 1. For parameter values such that:

$$
r\left(1-p_{G}\right)-p_{B} \geq \frac{L-\zeta-U}{H-L}
$$


and

$$
p_{G}-2 p_{B}<\frac{L-\zeta-U}{H-L}
$$

the unique perfect Bayesian equilibrium is one in which all G-type workers reject the first-period offer and all B-type workers accept it.

Proof of lemmal. Expressions (3a) and (3b) can be rewritten as

$$
U+r H+(1-r) w_{G} \geq w_{B}+w_{G}-\zeta
$$

and

$$
U+w_{G}<2 w_{B}-\zeta
$$

respectively. Expressions (4a) and (4b) say that if prospective employers offer a wage of $w_{G}$ to workers who reject the first period offer, and a wage of $w_{B}$ to workers who accept the first period offer, then it is optimal for G-type workers to reject the first-period offer and for B-type workers to accept it. Given these worker's equilibrium strategies, prospective employers choose a second-period wage of $w_{G}$ for laid-off workers who are unemployed during the first period and a wage of $w_{B}$ for laid-off workers who accept a job at the beginning of the first period. Thus, the strategies just described are equilibrium strategies.

$\underline{\text { Lemma 2. }}$ There is a perfect Bayesian equilibrium in which all $G$-type workers and a proportion $\tau$ of B-type workers wait unemployed when:

$$
\begin{array}{ll} 
& \eta\left(p_{G}-p_{B}\right)-p_{B} \leq \frac{L-\zeta-U}{H-L} \leq p_{G}-2 p_{B} \\
\text { and } \quad & r \geq \frac{\left(p_{G}-p_{B}\right)[H-L]-U-\zeta}{2\left(1-p_{B}\right)[H-L]-H}
\end{array}
$$

where $\eta$ is defined as: $\quad \eta=\frac{(1-r) \alpha}{(1-r) \alpha+(1-\alpha)}$

and $\eta$ is the probability that a $G$-type worker accepts a new job offer in the second period when all workers choose to reject the first period offer. $\tau$ is given by the following equation:

$$
\tau=\frac{\alpha(1-r)}{(1-\alpha)} \frac{\left\{\left(p_{G}-2 p_{B}\right)[H-L]-[L-\zeta-U]\right\}}{\left\{p_{B}[H-L]+[L-\zeta-U]\right\}}
$$

Proof of lemma 2. Suppose (5a) is true. Since, $w_{2}(\tau)$ ranges from $\left[\eta w_{G}+(1-\eta) w_{B}\right]$ to $w_{G}$ and is continuous, there must exist a $\tau \in[0,1]$ that satisfies (5a). Reordering expression (5b) and (5c), it is easy to see that they say the following: If prospective employers offer $w_{2}(\tau)$ to laid-off workers who 
are unemployed during the first period and $w_{B}$ to laid-off workers who accept the first-period job offer, G-type workers will strictly prefer to reject the offer while B-type workers will be indifferent between rejecting the first-period job offer or accepting it. Supposing that all G-type workers and a fraction $\tau$ of B-type workers reject the first-period job offer, then prospective employers will offer a wage of $w_{2}(\tau)$ to laid-off workers who wait one period unemployed and a first period wage of $w_{B}$ to workers who accept the first-period job. Therefore, the strategies described in this lemma are the equilibrium strategies.

\section{Lemma 3. There is a perfect Bayesian pooling equilibrium in which all types of laid-off workers} reject job offers in the first-period when the following conditions hold:

$$
\begin{aligned}
& \frac{L-U-\zeta}{H-L} \leq r\left(1-p_{B}\right)+\eta\left(p_{G}-p_{B}\right)(1-r)-p_{G} \\
& \frac{L-U-\zeta}{H-L} \leq \eta\left(p_{G}-p_{B}\right)-p_{B}
\end{aligned}
$$

Proof of lemma 3 . Notice that (6a) and (6b) imply that

$$
\begin{aligned}
& U+r H+(1-r)\left[\eta w_{G}+(1-\eta) w_{B}\right] \geq w_{B}+w_{G}-\zeta \\
& U+\eta w_{G}+(1-\eta) w_{B} \geq 2 w_{B}-\zeta
\end{aligned}
$$

Suppose that prospective employers offer $\left[\eta w_{G}+(1-\eta) w_{B}\right]$ to laid-off workers who were unemployed during the first period, and $w_{B}$ to laid-off workers who accept a job in the first period. Inequalities (7a) and (7b) say that both types of workers reject the first-period job offer and choose to wait one period unemployed. Supposing that all laid-off workers choose to wait unemployed one period, and observing an out-of-equilibrium employment history of accepting a second-period job by a worker, it is possible that prospective employers believe that they were observing a B-type worker. Those beliefs would lead them to offer that worker the following wage: $w_{B}$.

Under condition (1), I can also construct another hybrid equilibrium, described in remark 1 in the appendix. However, I find this equilibrium to be unsatisfactory as explained in the appendix.

In this model, the equilibrium with no voluntary unemployment (heorem 2) is also possible. 
Theorem 2. There is a perfect Bayesian equilibrium in which there is no voluntary unemployment when

$$
\frac{L-U-\zeta}{H-L}>r\left[1-\alpha\left(p_{G}-p_{B}\right)-p_{B}\right]-p_{G}
$$

Proof of theorem 2. Inequality (13a) can be rewritten as:

$$
\left[\alpha w_{G}+(1-\alpha) w_{B}\right]+w_{G}-\zeta>U+r H+(1-r)\left[\alpha w_{G}+(1-\alpha) w_{B}\right]
$$

On the other hand, since $w_{B}>0$, I have that:

$$
\left[\alpha w_{G}+(1-\alpha) w_{B}\right]+w_{B}-\zeta>U+\left[\alpha w_{G}+(1-\alpha) w_{B}\right]
$$

Inequalities (8b) and (8c) say that all laid-off workers choose to accept the first-period wage. Since all workers choose to work during the first period, firms offer them a first-period wage of $\left[\alpha w_{G}+(1-\alpha) w_{B}\right]$. Firms can have consistent beliefs that if the out-of-equilibrium action "being unemployed for one period" is observed, it would have been taken by a randomly selected worker. Thus, they can set the wage offered to workers who are unemployed during the first period to $\left[\alpha w_{G}+(1-\alpha) w_{B}\right]$.

However, under certain conditions, this equilibrium fails to satisfy the Cho-Kreps intuitive criterion (theorem 3 in appendix). The intuitive criterion in this model is as follows: Starting from an equilibrium with no voluntary unemployment, a worker choosing to remain unemployed is implicitly making the following statement: "I must have a positive probability of being recalled because those workers with no probability of being recalled would not choose unemployment, even if employers believed that only the high productivity laid-off workers choose unemployment." Theorem 4 and corollary 1 in the appendix show that the outcome equilibrium that satisfies the intuitive criterion is unique and must be one with voluntary unemployment as defined by lemmas 1 to 3 .

\section{The Optimal Equilibrium}

In this model, because of asymmetric information, workers may behave strategically and choose unemployment instead of a new job. Under certain parameter conditions, it is socially optimal for $G$-type workers to remain unemployed, in which case they may be recalled. ${ }^{4}$ This socially optimal equilibrium occurs when the expected gain from being recalled is greater than the G-type worker's one-period expected output with a new employer. 
Theorem 5. It is socially optimal for G-type workers to reject the first-period job and for all other types to accept it when:

$$
\left(1-p_{G}\right) r-p_{G}>\frac{L}{H-L}
$$

Proof. Inequality (9) can be rewritten as $r H+(1-r)\left[p_{G} H+\left(1-p_{G}\right) L\right]>2\left[p_{G} H+\left(1-p_{G}\right) L\right]$, which implies that the total (expected) output produced by a $G$-type worker when he waits one period unemployed is greater than his expected output when he chooses to work during both periods. Similarly, one can see that the total expected output of a $B$-type worker who works in both periods is greater than if he were to remain one period unemployed.

Inequality (9) always satisfies the intuitive criterion. When condition (9) holds, the equilibrium that maximizes expected output is one in which high-productivity laid-off workers remain unemployed in order to see whether they are recalled or not. This occurs when the probability of being recalled is sufficiently large. When condition (9) holds, the comparative advantage of a Gtype worker with his old employer is sufficiently large that having him wait unemployed maximizes social welfare. This occurs independently of whether, ex-post, the worker gets recalled or not.

Because condition (9) is more binding than condition (3a), G-type workers always choose to remain unemployed for one period whenever it is socially optimal for them to do so. However, Gtype workers may reject a first-period job, even though it may not be socially optimal. This results from workers receiving UI for which they only incur part of the cost.

\section{A Re-employment Bonus}

I now show that when it is socially optimal for G-type workers to reject the first-period job, there is a re-employment bonus that induces this equilibrium. Let $R^{*}$ be a re-employment bonus given to all workers who accept a new job within the first period. These assumptions are consistent with most re-employment bonus experiments in the United States.

Theorem 6. Let the government offer a re-employment bonus, $R^{*}$, to all laid-off workers who accept a new job at the beginning of period one when condition (9) is satisfied, such that:

$$
R^{*}=w_{G}-w
$$

\footnotetext{
${ }^{4}$ The criterion for social welfare is that the total expected output for the economy is maximized.
} 
where $w_{G}=p_{G} H+\left(1-p_{G}\right) L$, and $w$ is the wage the worker receives from his new employer. Then the unique perfect Bayesian equilibrium outcome is the fully separating equilibrium. This satisfies the intuitive criterion.

Proof of theorem 6. See appendix.

This bonus guarantees that all workers receive a first-period wage equal to the expected productivity of a G-type worker. By doing so, it encourages B-type workers to reveal their type. Thus, this bonus subsidizes the first-period job offered to a B-type worker. However, this subsidy has an upper bound so that G-type workers will still prefer to wait one period rather than take a first-period job. This upper bound guarantees that valuable job matches are not broken. To implement the bonus, $R^{*}$, the government only needs to know the expected productivity of G-type workers and a rough idea of $w .^{5}$

I now show that the re-employment bonus is Pareto improving. ${ }^{6}$

Lemma 4. For any initial equilibrium, when condition (9) holds, there exists a re-employment bonus, $R^{*}$, under which all workers' expected incomes are at least as high as without the bonus.

\section{Proof of lemma 4. See appendix.}

From the societal perspective, implementing a re-employment bonus, $R^{*}$, when the optimal equilibrium is the fully separating equilibrium, is always cost-effective. ${ }^{7}$ However, the costs of implementing such a bonus, $R^{*}$, may not be cost-effective from the perspective of the government as a whole. In this case, the costs of a bonus program are the bonus payments, and the benefits are the reduced UI payments and tax revenues on any earnings increases. For instance, when the economy is already in the optimal equilibrium, implementing a re-employment bonus only leads to a transfer of money from the government to B-type workers who would already have chosen to accept the first-

\footnotetext{
${ }^{5}$ Alternatively, the government could tax the signal, i.e., tax unemployment. However, several reasons undermine this alternative: (1) equity issues, (2) the role of unemployment insurance (UI) as a means to insure individuals against loss of wage income, and (3) to provide workers with enough time to search for a new good match or acquire training.

${ }^{6} \mathrm{My}$ criterion for a "Pareto improvement" requires that the expected income of each type of worker be not decreased.

${ }^{7}$ A societal perspective ignores bonuses and UI payments, as they are transfers between the government and individuals. From this perspective, the only condition for the bonus to be cost-effective is that the net gains in expected productivity exceed the administrative costs, which in this model are assumed to be zero. In general, administrative costs should be quite small, especially if the policy becomes permanent. Nonetheless, other
} 
period wage. However, implementing a re-employment bonus in the pooling equilibria - in which some or all B-type workers reject the first period job-may well be cost-effective if it encourages Btype workers to find a new job. For any initial equilibrium in which implementing the re-employment bonus, $R^{*}$, is optimal, I calculate the size of the re-employment bonus such that this policy is selffinancing. I then look at which conditions are needed for the re-employment bonus, $R^{*}$, to be selffinancing.

Let $R^{S F}$ be the self-financing re-employment bonus. $R^{S F}$ is self-financing in that the UI benefits plus the re-employment bonus can be paid for by the same tax revenue as the UI benefits paid in the absence of the bonus. I then analyze the necessary conditions for the re-employment bonus, $R^{*}$, to be cost-effective from the perspective of the government as a whole.

Theorem 7. Suppose the initial equilibrium is described by lemma 2 (i.e., only a fraction $\tau$ of $B$ type workers chooses to accept the first-period job). Then, the self-financing re-employment bonus is defined by

$$
R^{S F}=\tau[U+\zeta]
$$

and the necessary condition for the re-employment bonus, $R^{*}$, to be self-financing is

$$
U+\zeta \geq \frac{\left(p_{G}-p_{B}\right)}{\tau}[H-L]
$$

Suppose the initial equilibrium is described by lemma 3 (i.e., all workers choose to remain unemployed during period one). Then, the self-financing re-employment bonus is defined by

$$
R^{S F}=U+\zeta
$$

and the necessary condition for the re-employment bonus, $R^{*}$, to be self-financing is:

$$
U+\zeta \geq\left(p_{G}-p_{B}\right)[H-L]
$$

Proof of theorem 7. See appendix.

Not surprisingly, the size of the self-financing re-employment bonus increases with the fraction of Btype workers who choose unemployment. This occurs because the larger the fraction of B-type workers who wait unemployed, the higher the UI costs to the government and the greater the losses from payroll taxes.

issues may accompany the setting of a permanent bonus (see Meyer, 1995 and 1996; and Davidson and Woodbury, 1993.) 


\section{Empirical Results on Re-employment Bonuses}

This section reviews the empirically observed results from the re-employment bonus demonstrations in the United States, and examines whether the signalling model of temporary layoffs helps explain the empirical findings.

Four re-employment bonus demonstrations were conducted in the late 1980s in the United States. ${ }^{8}$ The evaluations of these re-employment bonus experiments indicated that the policies led to: (1) higher rates of exit from unemployment during the qualification period-the time within which a worker needs to find employment in order to qualify for the bonus; and (2) declines in weeks of UI receipt (Woodbury and Spiegelman, 1987; Corson, and Haimson, 1996; Decker, and O'Leary, 1992). However, (3) the benefit-cost analyses suggest that a re-employment bonus would generate small net losses for the unemployment insurance (UI) program, while society as a whole would break even (Meyer, 1995; and O’Leary, Spiegelman, and Kline, 1995).

Like the labor supply model and the search model, the signalling model of temporary layoffs is consistent with the above empirical findings. It can be shown that starting from any pooling or semi-separating equilibrium with unemployment, the implementation of a re-employment bonus, $R^{*}$, increases the probability of finding a new job for displaced workers and reduces the mean UI receipt for the eligible population. We have also shown in section III that implementing a re-employment bonus, $R^{*}$, when the optimal equilibrium is the fully separating equilibrium, is always cost-effective from the societal perspective.

Three additional empirical results from the evaluations of the re-employment bonuses demonstrations are difficult to interpret using a labor supply or search framework. First, Anderson (1990, and 1992) finds that there is no effect of the re-employment bonus on the new job hazard rate of workers who expect to be recalled. Second, O'Leary, Decker and Wandner (1997) find that using a higher probability threshold for targeting the re-employment bonus to workers with a high probability of UI exhaustion does not necessarily translate into a larger UI reduction. Third, evidence from the Pennsylvania demonstration finds that larger re-employment bonus offers do not necessarily reduce insured unemployment by more than smaller bonus offers.

These empirical findings can, however, be explained by the signalling model. First, given a re-employment bonus like the one described in theorem 6, the model predicts a higher new-job hazard rate during the qualification period for workers who do not expect to be recalled. But, consistent with Anderson (1990), the model predicts no effect of the bonus on the new-job hazard rate for those workers who expect to be recalled.

\footnotetext{
${ }^{8}$ The four re-employment bonus demonstrations were conducted in Illinois (1984-85), New Jersey (1985-86) Pennsylvania (1988-89), and Washington (1988-89).
} 
Second, the model also explains O'Leary, Decker and Wandner's results that using a higher probability threshold for targeting the bonus to workers with a high probability of UI exhaustion does not necessarily translate into larger UI reduction. Given the bonus described in this paper, those workers who expect to be recalled will wait for recall regardless of whether they are recalled ex-post or not. Thus, those who expect to be recalled but are not, end up having long unemployment spells (and probably exhausting UI benefits). Because this group of workers is awaiting recall, targeting them with a re-employment bonus - despite their high probability of UI exhaustion-does not translate into larger UI reduction. Thus, in this model targeting the re-employment bonus to workers with high probability of UI exhaustion does not necessarily translate into larger UI reduction.

Third, in this model, larger bonus offers do not necessarily translate into greater unemployment reduction. For a larger bonus to imply a greater unemployment reduction in the signalling model, the bonus offer must be greater than a given threshold above which laid-off workers who expect to be recalled choose to take a new job. For any bonuses below this threshold, a larger bonus size does not imply greater unemployment reduction.

\section{CONCLUSION}

By presenting an alternative framework for analyzing laid-off workers' behavioral responses to changes in the UI program — in particular, to a re-employment bonus - this paper suggests several policy implications that would be interesting to explore empirically in future research. First, targeting a re-employment bonus to laid-off workers who do not have a definite recall date does not guarantee that a valuable job match will be protected. ${ }^{9}$ This occurs because many laid-off workers who do not have a definite recall date end up being rehired by their originalemployer. For instance, Katz and Meyer (1990) find that in their sample of UI recipients, 63 percent of those workers who expected to be recalled but did not have a definite recall date were rehired by their former employer.

Second, determining the size of a re-employment bonus is crucial to the success of a reemployment bonus experiment. Laid-off workers have private information on their probability of being recalled. Therefore, a re-employment bonus can be used to give the correct incentives to displaced workers such that the bonus increases job search only among those workers with the least likelihood of being recalled. However, determining the size of a re-employment bonus is crucial to the success of the experiment: a too-small bonus may not be sufficient to stimulate job search among

\footnotetext{
${ }^{9}$ To avoid breaking valuable job-matches, the re-employment bonus experiments were usually not targeted to job-attached UI claimants, but rather to claimants who did not have a definite recall date. For instance, the Illinois and the New Jersey experiments excluded those workers with definite recall date and those who were members in unions using hiring halls. The Pennsylvania experiment excluded those workers with definite recall date within 60 days after benefit application.
} 
those whose former employee-employer match is no longer efficient; and a too- large bonus may break valuable job matches and be too costly to the UI program and from societal perspective. Unfortunately, the theoretic al model is too stylized to determine the optimal bonus size and qualification period. Thus, in the end, the issue must be settled empirically. Nonetheless, this paper indicates that further empirical analysis on the impact of the bonus by cause of displacement and initial recall expectations may be useful for designing optimal policies, in particular given the importance of recall expectations on laid-off workers' behavior.

Third, targeting the re-employment bonus to laid-off workers most likely to exhaust UI benefits may not be optimal, especially if these workers have valuable job-matches with their former employers. Most laid-off workers who expected to be recalled but end up taking new jobs tend to have much longer unemployment spells than observationally equivalent workers who did not expect to be recalled at the time of layoff (Katz and Meyer, 1990; and Anderson, 1992). Thus, those laid-off workers most likely to exhaust UI may not be searching for a new job, nor responding to a reemployment bonus during the bonus-qualification period. Improvements on the reduction of UI receipt may well occur if the re-employment bonus is targeted to those laid-off workers less likely to expect a recall, in addition to those most likely to exhaust UI. ${ }^{10}$

\footnotetext{
${ }^{10}$ In a permanent bonus setting, the profiling should be done-not by asking workers their expected probability of recall-but by assigning them a predicted expected probability of recall. This would prevent workers from reporting false recall expectations as a means of being eligible for the bonus.
} 


\section{REFERENCES}

Anderson, P., “Time-varying Effects of Recall Expectations, a Re-employment Bonus, and Job Counseling on Unemployment Durations," Journal of Labor Economics, 1992: 99-115. Previously, Industrial Relations Section, Working Paper no. 263, Princeton University March 1990.

Corson W., and P., Decker, "New Jersey Unemployment Insurance Re-employment Demonstration Project," Unemployment Insurance Occasional Papers 89-3, U.S. Department of Labor, Employment and Training Administration, Unemployment Insurance Service, 1989.

Corson W., and P., Decker, "Pennsylvania Re-employment Bonus Demonstration Final Report," Unemployment Insurance Occasional Papers 92-1, U.S. Department of Labor, Employment and Training Administration, Unemployment Insurance Service, 1992.

Corson W., and J. Haimson, "The New Jersey Unemployment Insurance Re-employment Demonstration Project: Six-Year Follow-Up and Summary Report," Unemployment Insurance Occasional Papers 96-2, Washington D.C., U.S. Department of Labor.

Cho, I., and, D. Kreps, "Signalling Games and Stable Equilibria," Quarterly Journal of Economics 102, 179221.

Davidson C., and S., Woodbury, “The Displacement Effect of Re-employment Bonus Programs," Journal of Labor Economics, 1993: 575-605.

Davidson C., and S., Woodbury, "Unemployment Insurance and Unemployment : Implications of the Reemployment Bonus Experiments," Upjohn Institute for Employment Research Staff Working Paper, April 1996. Decker, P., "The Impact of Re-employment Bonuses on Insured Unemployment in the New Jersey and Illinois Re-employment Bonus Experiments," The Journal of Human Resources, 1994: 718-41.

Decker P., and C., O'Leary, “An Analysis of Pooled Evidence from Pennsylvania and Washington Reemployment Bonus Demonstration," Unemployment Insurance Occasional Papers 92-7, U.S. Department of Labor, Employment and Training Administration, Unemployment Insurance Service, 1992.

Decker P., C., O'Leary, and S. Wandner, "Re-employment Bonuses and Profiling," Upjohn Institute for Employment Research Staff Working Paper 03-51, January 2003.

Gibbons, R., and L. Katz, "Layoffs and Lemons," Journal of Labor Economics, October 1991: 351-380.

Katz, L., "Layoffs, Recall and the Duration of Unemployment,” NBER Working Paper No. 1825, 1986.

Katz, L., and B. Meyer, "Unemployment Insurance, Recall Expectations, and Unemployment Outcomes," Quarterly Journal of Economics, November 1990: 973-1002.

Kline, K., C., O’Leary, R., Spiegelman, “The Washington Re-employment Bonus Experiment Final Report,” Unemployment Insurance Occasional Papers 92-6, U.S. Department of Labor, Employment and Training Administration, Unemployment Insurance Service, 1992.

Ma, A., and A. Weiss, "A Signalling Theory of Unemployment," European Economic Review 37, 1993: 135157.

Meyer, B., "Lessons from the U.S. Unemployment Insurance Experiments," Journal of Economic Literature, 
vol. XXXIII, 1995:91-131.

Meyer, B, "What have we learned from the Illinois Re-employment Bonus Experiment?" Journal of Labor Economics, 1996:26-51.

Rodriguez-Planas, N., "Signalling in the Labor Market: New Evidence on Layoffs, and Plant Closings," William Davidson Institute Working Paper 610, 2003.

Woodbury, S., and R., Spiegelman, "Bonuses to Workers and Employers to Reduce Unemployment: Randomized Trials in Illinois," American Economic Review, 1987:513-30. 